\section{Punished extinction: Facilitation or increased resistance to extinction}

\author{
DAVID MYERS and JACK SANDLER \\ University of South Florida, Tampa, Fla. 33620
}

In order to investigate the effects of resistance to exinction of changes in stimulus conditions from acquisition to extinction of an avoidance response, four rats were presented with the following extinction conditions: regular, punished regular, delay (CS continued independently of S's behavior), and punished delay. Using the regular condition as a control, the punished conditions resulted in facilitation for the first two or three trials followed by reduced resistance to extinction. No systematic changes were found as a function of the delay condition. These results were interpreted as support for a discrimination hypothesis.

The conventional procedure for studying resistance to extinction of a signaled avoidance response usuatly involves the termination of the contingency between the avoidance response and the shock (US). Katzev (1967) pointed out, however, that responding in such a procedure results in CS termination and adventitious shock avoidance-thus, the extinction condition closely approximates the circumstances present in acquisition. In addition, he provided evidence that changing the CS termination consequence reduced resistance to extinction. This is in accord with the discrimination hypothesis (Church, 1963), which suggests that as the degree of change from acquisition to extinction is increased, the extinction condition is more discriminable from acquisition and results in decreased resistance to extinction. Thus, an analysis of the differences between acquisition and extinction should be of importance in determining resistance to extinction of an avoidance response.

On the other hand, evidence from several shock-avoidance and shock-escape studies (Solomon, Kamin, \& Wynne, 1953; Campbell, Smith, \& Misanin, 1966; Beecroft, 1967; Brown et al, 1964) suggests that some changes do not result in reduced resistance to extinction and, in fact, enhance resistance to extinction. Sandler et al (1966) and Church (1963) have suggested that such results may be a function of the discriminative properties of shock in the sense that prior responding in the presence of shock produced shock escape. Similarly, extending the CS in the presence of responding may also provide a discriminative stimulus for further responding. Thus, an analysis of resistance to extinction of an avoidance response must consider not only the changes which are introduced, but the correlation between these changes and the animal's prior response history. Conceivably, presenting response-contingent shock and extending the CS beyond the occasion of the response may involve two competing processes, one enhancing and the other reducing resistance to extinction. The present study was designed to study the effects of two such changes.

\section{SUBJECTS} rats, approximately 120-150 days old at the beginning of the experiment. APPARATUS

A Grason-Stadler operant conditioning chamber in a lightproof sound-attenuating chamber was used. The conditioning chamber was equipped with a bar, $10.5 \mathrm{~mm}$ above the grid floor, which extended $1.5 \mathrm{~mm}$ into the chamber. Shock was delivered via a scrambling device that randomly changed the polarity of the grid. Automatic programming equipment and the cumulative recorder were located in an adjoining room.

$$
\text { PROCEDURE }
$$

During the first 30 trials, the animals were trained to escape shock by means of successive approximations to the barpress response. Trials were presented on a VI 30-sec schedule and introduced by a 5 -sec audible clicker (CS), terminating in a continuous $0.2-\mathrm{mA}$ shock. A response in the presence of the clicker avoided shock, and a response in the presence of shock terminated shock. Trials 31-100 (and all subsequent trials) employed a pulsed $0.5-\mathrm{mA}$ shock (D'Amato et al,
The Ss were four naive Fischer-344
1964) that was presented in cycles of $0.5 \mathrm{sec}$ on and 5 sec off.

The second session and all subsequent sessions consisted of 200 trials. The first 50 trials employed $0.5 \cdot \mathrm{mA}$ shock, followed by 150 trials with $1.0-\mathrm{mA}$ shock. Starting with Trial 1 in Session 3, the shock was increased and maintained at $2.0-\mathrm{mA}$ shock for the rest of the experiment.

Animals were run until they met a criterion of 2 consecutive days of 45 avoidance responses in three of four blocks of 50 trials. Following criterion performances, they were placed in one of four extinction conditions: regular (R), punished regular (PR), delayed (D), and punished delayed (PD). The $R$ condition consisted of eliminating the contingency between the avoidance response and the shock US and terminating the clicker contingent upon a response. The $P R$ condition consisted of $R$ plus $1.0-\mathrm{mA}$ response-contingent shock. In the $D$ condition, the contingency between the avoidance response and the shock US was eliminated, but the clicker was continued during the 5-sec interval, independent of responding. The $P D$ condition consisted of $\mathrm{D}$ plus $1.0-\mathrm{mA}$ response-contingent shock (shock was delivered on the occasion of every response). S remained in the extinction session until it met the criterion of 50 trials without an avoidance response. On the following day, avoidance reacquisition was presented. Each animal was required again to meet the criterion as above. Table 1 presents the experimental sequence for each animal. It should be noted that each condition appears once in each column (unit) of the experimental sequence.

\section{RESULTS}

\section{Resistance to Extinction}

Figure 1 shows the number of trials to reach the extinction criterion for each animal in each condition. (The connection of data points does not imply continuity of conditions.) Inspection of Fig. 1 reveals that the greatest resistance to extinction occurred in $R$. In seven of eight $R$ extinction presentations, $S s$ required 60 or more trials to reach extinction. Since this condition represents the conventional extinction procedure, it may be regarded as a baseline against which the other experimental

Table 1

Order of Presentation of Conditions for Each Animal

\begin{tabular}{|c|c|c|c|c|c|c|c|c|}
\hline \multirow{2}{*}{$\frac{\text { Ss }}{1}$} & \multicolumn{4}{|c|}{ Conventional } & \multicolumn{4}{|c|}{ CS Delay } \\
\hline & $\mathbf{R}$ & PR & $\mathbf{R}$ & PR & $\mathrm{D}$ & PD & $\mathbf{D}$ & PD \\
\hline \multirow[t]{2}{*}{2} & PR & $\mathbf{R}$ & PR & $\mathrm{R}$ & PD & $\mathbf{P}$ & PD & $P$ \\
\hline & \multicolumn{4}{|c|}{ CS Delay } & \multicolumn{4}{|c|}{ Conventional } \\
\hline 3 & PD & D & $P D$ & D & PR & $\mathbf{R}$ & PR & $\mathbf{R}$ \\
\hline 4 & $\mathrm{D}$ & $\mathrm{PD}$ & $\mathbf{P}$ & PD & $\mathbf{R}$ & PR & $\mathbf{R}$ & $\mathbf{R}$ \\
\hline
\end{tabular}




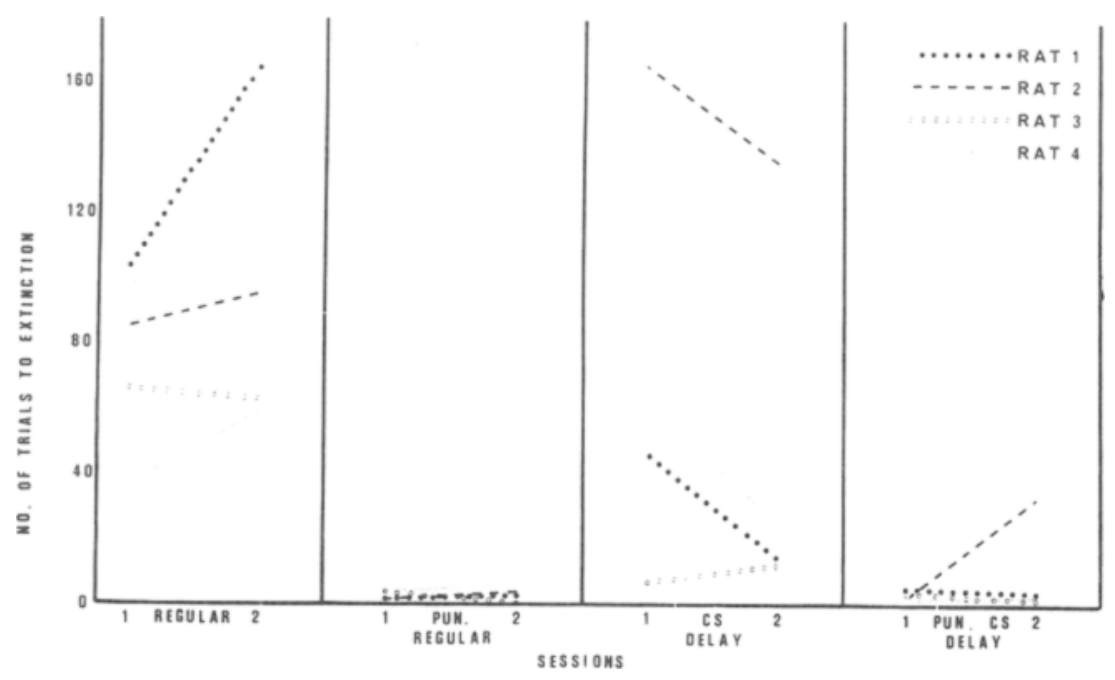

Fig. 1. Total number of trials to extinction for each animal. Each animal received two extinction sessions in each condition.

conditions may be assessed.

In contrast to the $R$ condition, the $P R$ and $P D$ conditions resulted in complete suppression of responding within three or four trials in every presentation except one-Rat 2, PD 2. This animal responded on the first four trials and made only one additional response on the 33rd trial. 'The results of the $D$ condition are ambiguous in that one animal (Rat 2) displayed increased resistance to extinction and two animals displayed decreased resistance to extinction, while there was little change in resistance to extinction in the fourth animal.

In brief, the greatest decrease in resistance to extinction was found in the punished conditions and intermediate resistance to extinction

in the delay condition. No differential effects were observed between the PR and PD conditions in terms of resistance to extinction.

\section{Facilitation}

Figure 2 shows the total number of responses made in each extinction condition for blocks of three trials. Only the first 15 trials of each condition are shown, since the rate had either stabilized or was suppressed at this point. Again using the $R$ condition as a baseline, the first presentation of response-contingent shock (i.e., in the PR and PD conditions) resulted in an increase in response rate in all presentations. These effects were also obtained in the second presentation of these conditions in all but two cases (Rat 3 , PR 2 and Rat 1, PD 2). In each

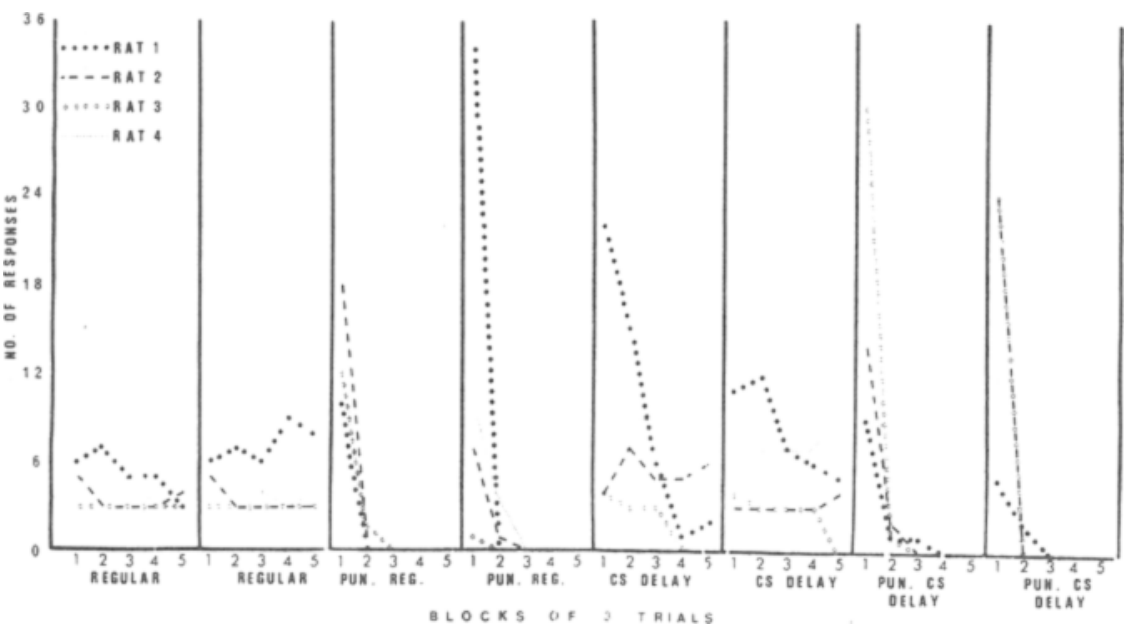

Fig. 2. Total number of responses in each extinction condition for each animal. Reacquisition occurred between each extinction session. instance, however, this initial response facilitation was replaced by complete response suppression by the fourth or fifth trial. There were no systematic changes evident in the eight presentations of the delay condition.

In summary, the greatest initial facilitation, as well as the least resistance to extinction, occurred in the punished conditions, and the greatest overall resistance to extinction occurred in the regular condition, with no systematic change occurring in the delay condition.

\section{DISCUSSION}

The results of the $P R$ and $P D$ conditions are in agreement with reasoning that is provided from three separate, but compatible, positions. Sandler et al (1966) and Church (1963) have argued that resistance to extinction is increased or decreased as the discriminability of extinction either decreases or increases. McKearney (1968) and Stretch et al (1968) provide evidence that the effects of a strong stimulus, such as shock, are not immutable or invariant but are dependent upon the schedule of shock presentation and the ongoing behavior at the time of shock presentation. Herrnstein \& Hineline (1966) have argued that avoidance behavior is maintained as a function of shock-frequency reduction. Thus, at acquisition criterion, animals rarely encountered shock, but upon presentation of the punishment arrangement, shock occurred with each response, enhancing the discriminability of the extinction phase. Initially, the shock's discriminative properties (as a function of earlier training) resulted in facilitation, but very rapidly this discriminative effect was replaced by a suppressive effect. Thus, the increase in shock frequency enhanced the discriminability of extinction and resulted in reduced resistance to extinction.

One may also interpret these results in terms of the "flooding," or response prevention thesis proposed by Baum (1970) and Baum \& Oler (1968). Thus, confining rats to a fearful situation for a certain period of time results in reduced resistance to extinction. Similarly, animals exposed to shock which they previously avoided resulted in reduced resistance to extinction. It must also be noted that the avoidance response was not blocked in this study, and this is an integral part of Baum's methodology.

In summary, it might be generally assumed that as the number of conditions that are changed increases, resistance to extinction decreases. However, this generalization is qualified by the interaction between these changes and prior response 
history. Thus, changing the CS contingency resulted only in tentative evidence for reduced resistance, while presenting a shock contingent upon a response resulted in significant changes in resistance to extinction. These effects may be interpreted in terms of the competing processes which are involved.

\section{REFERENCES}

BEECROFT, R. S. Near-goal punishment of avoidance running. Psychonomic Science, $1967,8,109-110$.

BAUM, M, Extinction of avoidance responding through response prevention (flooding). Psychological Bulletin, 1970, 74, 276-284.

BAUM, M.. \& OLER, I. D. Extinction of avoidance responding. Psychological Reports, 1968, 23, 807-813.

BROWN, J, S.. MARTIN, R. C., \& MORR $O W, M$. W. Self-punitive behavior in the rat: Facilitative effects of punishment of resistance to extinction. Journal of Comparative \& Physiological Psychology, 1964, 57, 127-133.

CAMPBELL, B. A., SMITH, N. R., \& MISANIN, J. B. Effects of punishment on extinction of avoidance behavior: Avoidance-avoidance conflict or vicious circle behavior? Journal of Comparative $\&$ Physiological Psychology, 1966, 62. 495-498.

CHURCH, R. M. The varied effects of punishment on behavior. Psychological Review, 1963, 70, 369-402.

D'AMATO. M. R.: KELLER, R. D., \& DI CARA, L. Facilitation of discriminated avoidance leaming by discontinuous shock. Journal of Comparative \& Physiological Psychology. $1964,58,344-349$.

HERRNSTEIN, R. J., \& HINELINE, P. N. Negative reinforcement as shock-frequency reduction. Journal of the Experimental Analysis of Behavior. 1966, 9, 421-430.

KATZEV, R. Extinguishing avoidance responses as a function of delayed warning signal termination. Journal of Experimental Psychology, 1967, 75. 339-344.

MCKEARNEY, J. W. Maintenance of responding under a fixed-interval schedule of electric shock presentation. Science, $1968,160,1249-1251$

SANDLER, J.. DAVIDSON, R. S. GREENE, W. E., \& HOLZSCHUH, R. D. Effects of punishment intensity on instnumental avoidance behavior. Journal of Comparative \& Physiological Psychology, 1966, 61, 21 2-216.

SOLOMON, R. L.. KAMIN, L. J. \& WYNN, L. C. Traumatic avoidance learning: The outcomes of several extinction procedures with dogs. Journal of Abnormal \& Social Psychology, 1953, 48, 291-302.

STRETCH, R., ORLOFF, E. R., \& DALRYMPLE, S. D Maintenance of responding by fixed-interval schedule of electric shock presentation in squirrel monkeys. Science, $1968,162,583-585$.

\section{Omission training effects following VI and FI pretraining*}

\section{JEFF S. TOPPING, JOHN W. PICKERING, and JERRY A. JACKSON $\dagger$ Mississippi State University, State College, Miss. 39762}

The present study assessed the relative response-elimination properties of three omission training procedures following VI and FI 20-sec pretraining. During omission training, response-reinforcement and reinforcement-reinforcement intervals both were 5,20 , or $35 \mathrm{sec}$. Regardless of the pretraining reinforcement schedule, the 5- and $35-\mathrm{sec}$ groups showed the greatest and most rapid response reduction. However, findings from a durability test indicated that the response elimination of the 5-sec groups was very transient, whereas it was long lasting in the 20-and $35-\mathrm{sec}$ groups.

In recent years, attention has focused on the various techniques for eliminating responding. One particular response-elimination technique which has generated considerable research is omission training (OT), in which $\mathrm{S}$ is reinforced for omitting a previously reinforced response. Several investigations have shown OT to be a successful method of response

* Supported in part by National Science Foundation Institutional Grant for Science R 200J-4450.

tRequests for reprints should be sent to Jeff S. Topping, P.O. Drawer PF, Mississippi State University. State College, Miss. 39762. elimination (Baer, Peterson, \& Sherman, 1967; Long, 1962, 1963; Mishkin \& Weiskrantz, 1959 ; Reynolds, 1961; Sherman, 1965). In addition, OT alone has been observed to produce relatively more durable effects than extinction training alone, extinction training plus punishment, or OT plus punishment (Uhl \& Garcia, 1969; Uhl \& Sherman, 1971).

Two temporal parameters are involved in the OT procedure: (1) a response-reinforcement interval which specifies the time that each response postpones reinforcement, and (2) a reinforcement-reinforcement interval which specifies the time between reinforcements if no responses are emitted. Recent investigations in our laboratory have suggested that the relationship between these two temporal parameters and the pretraining schedule of reinforcement might be crucial in determining the effects of OT.

The present experiment attempted to provide additional information on the relationship between $O T$ and the pretraining schedule of reinforcement. This aim was accomplished by pretraining Ss on either a variable-interval (VI) 20 -sec or fixed-interval (FI) 20-sec schedule and then switching to OT, in which the response-reinforcement and reinforcement-reinforcement intervals were greater than, equal to, or less than the numerical value of the pretraining schedule.

\section{SUBJECTS}

Twelve experimentally naive male White King pigeons, individually housed, served as Ss and were maintained at approximately $75 \%$ of their free feeding weights for a period extending from 1 week prior to the experiment through the duration of the experiment.

$$
\text { APPARATUS }
$$

A standard three-key pigeon chamber, $19 \frac{1 / 2}{2} \times 14 \times 14$ in., was located within a sound-attenuating ventilated cubicle. The 1 -in.-diam keys were centered, $10 \mathrm{in}$. from the floor and 4 in. apart, on a metal panel separating the S's chamber from the area containing the stimulus- and food-presenting mechanisms. Only the center key was employed in the present experiment, and the remaining keys were covered by metal plates. A minimum force of $15 \mathrm{~g}$ was required to operate the $\mathrm{key}$, and responses produced auditory feedback. A one-plane readout allowed white light to be projected on the response key, and the experimental chamber was diffusely lighted from above by two small lightbulbs. Three inches from the bottom of the intelligence panel was centered a $2 \times 2 \mathrm{in}$. opening, through which a solenoid-operated grain hopper could be presented. Reinforcement consisted of a $5 \mathrm{sec}$ access to the illuminated grain hopper. A white-noise generator functioned throughout the experiment to mask extraneous noises, and a blower regulated the temperature inside the chamber. A system of automatic controlling and recording equipment allowed the data to be collected in a separate room.

\section{PROCEDURE}

As soon as Ss were reduced to $75 \%$ of their ad lib weights, they were given 2 days of magazine training, during which 50 reinforcements were 